\title{
Precision targeting by phosphoinositides: how PIs direct endomembrane trafficking in plants
}

Sort title: PIPs and vesicular trafficking in plants

Lise C. Noack and Yvon Jaillais\#

Laboratoire Reproduction et Développement des Plantes, Univ Lyon, ENS de Lyon, UCB

Lyon 1, CNRS, INRA, F-69342, Lyon, France

\# Corresponding author: yvon.jaillais@ens-lyon.fr

\begin{abstract}
:
Each phosphoinositide (PI, also known as phosphatidylinositol phosphate, polyphosphoinositide, PtdInsP or PIP) species is partitioned in the endomembrane system and thereby contributes to the identity of membrane compartments. However, membranes are in constant flux within this system, which raises the questions of how the spatiotemporal pattern of phosphoinositides is established and maintained within the cell. Here we review the general mechanisms by which phosphoinositides and membrane trafficking feedbacks on each other to regulate cellular patterning. We then use the specific examples of polarized trafficking, endosomal sorting and vacuolar biogenesis to illustrate these general concepts.
\end{abstract}

\section{Graphical abstract:}

\section{Highlights:}

- PIPs are biochemical and biophysical landmarks that specify membrane identity

- PIPs and small GTPases couple membrane identity switches with trafficking

- Two distinct PIP cascades exist in plants, centered around early and late endosomes

- $\mathrm{PI}(3) \mathrm{P}$ and $\mathrm{PI}(3,5) \mathrm{P}_{2}$ regulate vacuolar biogenesis, endosomal sorting and autophagy

- PIP patterning defines membrane domains for polarized exocytosis and endocytosis

\section{Keywords:}

PtdIns, phosphoinositide, cell polarity, endocytosis, exocytosis, exocyst, actin, vacuole, autophagy, auxin, tip growth, root hair, pollen tube, PIP, phosphatidylinositol 3-phosphate, phosphatidylinositol 4-phosphate, phosphatidylinositol 4-5 bis-phosphate, phosphatidylinositol 3-5 bis-phosphate, $\mathrm{PI}(3) \mathrm{P}, \mathrm{PI}(4) \mathrm{P}, \mathrm{Ptd} \operatorname{Ins}(4) \mathrm{P}, \mathrm{PI}(4,5) \mathrm{P}_{2}$, PtdIns(4,5) $\mathrm{P}_{2}$ 


\section{Introduction:}

Membrane identities are acquired by the combined presence of specific lipids and proteins on each membrane. For example, small GTPases (Rab, Rho and Arf) are important contributors of organelle identity [1]. On the lipid side, major determinants of membrane identities are phosphoinositides, which are anionic phospholipids with an inositol head group that can be phosphorylated at various positions on their polar head (Figure 1a) [2]. Both groups of molecules also coordinate trafficking between different membranes and specific mechanisms are in place to ensure their correct spatiotemporal distribution. Here, we review the mechanisms by which phosphoinositides contribute to both membrane trafficking and organelle identity. Since the general mechanisms linking anionic phospholipids and trafficking are shared between all eukaryotes, we first describe these generic concepts, including plant examples when available. We then describe the subcellular localization of phosphoinositides in plants. Finally, to illustrate the aforementioned concepts, we use the examples of vacuolar sorting and polarized trafficking, notably in the context of tip growth.

\section{General concepts linking phosphoinositides and membrane trafficking in eukaryotes}

\section{- Importance of phosphoinositide cyclical and cascade regulation}

Phosphatidylcholine and phosphatidylethanolamine constitute more than $60 \%$ of total phospholipids, followed in abundance by phosphatidylinositol, phosphatidylglycerol, phosphatidylserine, and phosphatidic acid. Phosphatidylinositol is mainly found in the luminal side of the Endoplasmic Reticulum but a minor amount is exposed on organelle cytosolic leaflets, where it is phosphorylated into various phosphatidylinositol phosphate species (so called phosphoinositides or PIs). In all eukaryotes, phosphoinositides are quantitatively minor lipids, accounting for less than one percent of total phospholipids. Yet, they are set apart from other lipids because they are rapidly interconverted into one another by the action of lipid kinases and phosphatases, allowing their spatiotemporal control by cyclical regulation (Figure 1b) [1]. The combined action of kinases and phosphatases produces up to five phosphoinositides in plants, four of which have been involved in membrane trafficking (PI(3)P, PI(4)P, PI(4,5) $\mathrm{P}_{2}$ and $\mathrm{PI}(3,5) \mathrm{P}_{2}$ ) (Figure 1c) $[2,3]$. In plants, $\mathrm{PI}(4) \mathrm{P}$ constitutes about $80 \%$ of phosphoinositides, followed in abundance by $\mathrm{PI}(4,5) \mathrm{P} 2, \mathrm{PI}(3) \mathrm{P}$ and $\mathrm{PI}(3,5) \mathrm{P} 2$.

Phosphoinositides are not only cycling between two states, but can cascade from one species to another and then another. In animals, a classical example of phosphoinositide cascade happens along the endocytic pathways [4]. This PI cascade starts from $\mathrm{PI}(4,5) \mathrm{P}_{2}$ at the plasma membrane (PM), utilizes transient accumulation of $\mathrm{PI}(4) \mathrm{P}$ and $\mathrm{PI}(3,4) \mathrm{P}_{2}$ during endocytosis, and leads to accumulation of $\mathrm{PI}(3) \mathrm{P}$ in early endosomes and then $\mathrm{PI}(3,5) \mathrm{P}_{2}$ in late endosomes [4]. By contrast, two shorter, largely independent phosphoinositide cascades exist in plants that are centered on early (trans-Golgi Network/Early Endosomes; TGN/EE) and late (Late Endosomes/Multivesicular Bodies; LE/MVB) endosomes (Figure 1c). Such cascades are a central theme in membrane trafficking as they allow membrane identity to evolve dynamically during the course of trafficking [1].

\section{- Phosphoinositides act as biochemical landmarks to recruit trafficking regulators}

By analogy to the histone code, phosphoinositides generate a "lipid code" that specifies membrane identity. The three corner stones of the histone code hypothesis are the presence of proteins that can create, remove and read marks on histones (so called writer, eraser and reader modules). Lipid kinases and phosphatases represent writer and eraser molecules in such lipid code hypothesis. Phosphoinositide-specific phospholipases C (PI-PLCs) constitute another eraser module that terminates the PI cycle by metabolizing $\mathrm{PI}(4) \mathrm{P}$ and $\mathrm{PI}(4,5) \mathrm{P}_{2}$ into Diacylglycerol (DAG) and soluble inositols (Figure 1b, note that the function of soluble 
inositols in endomembrane trafficking are not reviewed in this paper). The reader module is embodied by the presence of stereospecific lipid binding domains in many proteins (Figure 1b) [5]. Most trafficking regulators possess themselves such domains, which couple membrane recruitment and trafficking regulation. For instance, the three trafficking regulators AtSORTING-NEXINs (AtSNXs), PLEKSTRIN-HOMOLOGY1 (AtPH1) and FYVEDOMAIN-PROTEIN1/FYVE-DOMAIN-PROTEIN-REQUIRED-FOR-ENDOSOMAL-

SORTING1 (FYVE1/FREE1) are targeted to PI(3)P-containing endosomes via a PHOX (PX), PLECKRTSIN-HOMOLY (PH) or Fab1-YOTB-Vac1-EEA1 (FYVE) domain, respectively [6-10].

\section{- Phosphoinositides cooperate with small GTPases to drive membrane traffic}

Phosphoinositides are intimately linked with small GTPases (e.g. Rab, Arf and Rho), which are themselves master regulators of membrane trafficking [1]. Many phosphoinositide writer/eraser modules are effectors of activated GTPases, notably Rab proteins (Figure 1d). GTPase activities are also regulated by phosphoinositides and numerous GTPase-activatingproteins (GAPs) and GTPase-exchange-factors (GEFs) contain a lipid binding domain that drives their membrane association (Figure 1e). In addition, there are many examples of proteins that are recruited to a specific membrane via the coincidence binding of a phosphoinositide and a small GTPase (Figure 1f). For instance, RabA4b recruits PI4K $\beta$ s to control PI(4)P production in secretory vesicles emerging from the TGN/EE [11]. In turn, coincident detection of PI(4)P and RabA4b in the TGN/EE targets the PLANT-U-BOX13, which regulates the trafficking of the pattern-recognition receptor FLAGELININSENSITIVE2 [12].

\section{- Phosphoinositides influence membrane deformation and surface charges}

Phosphoinositides have a large head group that favor membrane with a positive curvature, for example in the bud of growing vesicles (Figure 2a) [13]. Anionic phospholipids also control membrane electrostatics by modulating surface charges in the cytosolic leaflet of membranes (Figure 2a, b) [14]. The plant PM has a specific electrostatic signature that is driven by PI(4)P and recruits proteins with polybasic sequence(s) (Figure 2b, c) $[14,15]$. Interestingly, certain trafficking regulators are recruited to membrane through the coincident detection of curvature and electrostatics (Figure 2d) $[5,16]$. In turn, some of these proteins with a Bin-AmphyphisinRvs (BAR) domain, further induce membrane deformation; linking electrostatic and curvature regulation during trafficking $[5,17]$. Phosphoinositides also recruit coat proteins, such as the Adaptor Protein (AP) complexes involved in Clathrin-coated vesicle formation (Figure 2e) [4], or the retromer, involved in endosome tubulation (Figure 2f) [17,18]. In addition, phosphoinositides recruit and activate the actin polymerization machinery, which generates a motile force required for membrane deformation and vesicle motion (Figure 2e and f) $[18,19]$.

\section{The localization of phosphoinositides in plants}

Studying lipid localization is complex. Endogenous lipids are not easily tagged by fluorescent moieties, lipid fixations are difficult to achieve, and phosphoinositides may diffuse or traffic away from their site of synthesis [2]. Yet, the localization of phosphoinositides in plants is getting clearer (Figure 3a), thanks to the combinatorial use of: i) genetically encoded biosensors (i.e. fluorescent protein fused with stereospecific LBD), ii) mutants impaired in phosphoinositide homeostasis, and iii) localization studies of plant writer/eraser/reader proteins (see Figure $3 \mathrm{~b}$ for a summary of writer/eraser known localization) $[2,3]$. Some notable differences can be noted between plants and animals. A prime example is the massive accumulation of PI(4)P at the plant PM (Figure 3a); whereas in animals, PI(4)P prominently resides in the Golgi/TGN compartments and to a lesser extent at the PM [15]. In addition, 
$\mathrm{PI}(3) \mathrm{P}$ labels late endosomes in plants and early endosomes in animals [20,21]. By contrast, $\mathrm{PI}(4,5) \mathrm{P}_{2}$ localization at the $\mathrm{PM}$ and $\mathrm{PI}(3,5) \mathrm{P}_{2}$ in LE/MVB are conserved in eukaryotes [2123].

\section{Phosphoinositides in endosomal sorting and vacuole biogenesis}

The central vacuole is a plant specific organelle that can act both as a lytic and/or storage organelle [24]. Phosphoinositides, in particular the $\mathrm{PI} \rightarrow \mathrm{PI}(3) \mathrm{P} \rightarrow \mathrm{PI}(3,5) \mathrm{P}_{2}$ cascade (Figure $1 \mathrm{c})$, are involved in endosomal sorting events leading to membrane protein degradation or retrieval, vacuolar morphogenesis and autophagy.

\section{- $P I(3) P$ and PI(3,5)P2 sort PM proteins toward degradation or recycling}

After endocytosis, membrane proteins can recycle back to the PM or be targeted to the vacuole for degradation. LE/MVBs mature from TGN/EE, which gradually loses PI(4)P on its membrane and acquires PI(3)P together with the RabF protein ARA7/RabF2b (Figure 3c) $[25,26]$. PI(3)P is synthetized by the phosphatidylinositol 3-kinase (PI3K) VACUOLAR PROTEIN SORTING34 (VPS34), while the concomitant PI(4)P hydrolysis might be regulated by ROOT-HAIR-DEFECTIVE4 (RHD4)/ AtSUPRESSOR-OF-ACTIN7, a PI(4)P phosphatase that localizes in the TGN/EE (Figure 3b) [27].

Protein sorting during the maturation of TGN/EE into LE/MVB is orchestrated by the antagonistic activities of the ENDOSOMAL-SORTING-COMPLEX-REQUIRED-FORTRANSPORT (ESCRT) and the retromer complexes. ESCRT complexes mediate the internalization of ubiquitinated proteins into intraluminal vesicles of MVB/LE prior to their fusion with the lytic vacuole, where proteins are degraded. The retromer complex is involved in the retrieval of membrane proteins prior to their internalization in intraluminal vesicles, thereby allowing their subsequent recycling. In both cases, the function of these antagonistic complexes is intimately linked with PI(3)P (Figure 3c). Indeed, the plant specific ESCRT component FYVE1/FREE1 localizes in LE/MVB by binding concomitantly to PI(3)P, ubiquitinated cargos and ESCRT-I proteins [8,9,28,29]. The seedling lethal fyvel/freel mutant shows MVB and vacuole defects and fails to target ubiquitinated proteins to the vacuole for degradation, which instead mislocalize to the tonoplast [9,29]. In addition, the retromer components AtSNXs are also targeted to LE/MVB by PI(3)P [6,7]. In snxl and retromer mutants, the PIN auxin efflux carriers are not recycled back to the PM efficiently and are instead targeted to the vacuole for degradation [30-32]. The AtSNX1-interacting protein CYTOPLASMIC-LINKER-ASSOCIATED-PROTEIN (CLASP) links AtSNX1containing endosomes with cortical microtubules to regulate PIN2 trafficking [33]. AtSNX1 also interacts with phosphatidylinositol 3-phosphate 5-kinases (PI(3)P5Ks) from the PHOSPHOINOSITIDE-KINASE-FYVE-FINGER-CONTAING (PIKfyve)/FAB1 family (Figure 1c, g), which regulates AtSNX1, CLASP and PIN2 localization [34].

\section{- Phosphoinositides and the regulation of vacuole morphology}

Phosphoinositides control the biogenesis and morphology of the central vacuole. The SOLUBLE-NSF-ATTACHMENT-RECEPTOR (SNARE) protein VTI11 is involved in the fusion of LE/MVB with the vacuole [24]. vtil1 mutants harbors small unfused vacuoles, a phenotype that is rescued by inhibition of PI3K activity [35]. fyvel/freel and retromer mutants also accumulates small fragmented vacuoles, supporting a role for PI(3)P in this process $[9,29,31,32,36]$. It is likely that $\mathrm{PI}(3) \mathrm{P}$-dependent endosomal sorting via the ESCRT and retromer complexes is important for the correct trafficking and localization of SNARE proteins involved in vacuole fusion. 
PI(4)P also connects SNARE trafficking and vacuole morphology [37,38], although the mechanisms are still unclear and could be indirect. However, actin is important to shape vacuole morphology $[35,38]$. Transient PI(4)P production has recently been described as an important regulator of actin synthesis on endosomal membranes in animal cells [18]. It is therefore possible that a similar transient pool of PI(4)P might locally regulates vacuolar dynamics and/or sorting function at the LE/MVB, possibly by controlling actin dynamics. The notion that phosphoinositides might regulate actin dynamics in the late secretory pathway is supported by the vacuolar morphology defects displayed by loss- and gain-of-function mutants in AtSUPPRESSOR-OF-ACTIN genes (AtSAC2 to AtSAC5) [39]. SAC proteins are phosphoinositide phosphatases (Figure 1c and 3b). AtSAC2-5 are homologous to the Golgilocalized AtSAC1 protein, which has a 5-phosphatase activity toward $\mathrm{PI}(3,5) \mathrm{P}_{2}$ (Figure $3 \mathrm{~b}$ ) [40]. AtSAC2-5 localize on the tonoplast and might control vacuolar morphology by promoting $\mathrm{PI}(3,5) \mathrm{P}_{2}$ hydrolysis and $\mathrm{PI}(3) \mathrm{P}$ production in this compartment (Figure $3 \mathrm{a}$ and $\mathrm{b}$ ). However, it remains to be determined whether AtSAC2-5 function actually links actin dynamics with phosphoinositide homeostasis to regulate vacuole morphogenesis.

\section{- PI(3)P orchestrates autophagy}

Autophagy is a cellular degradation pathway that is initiated by the encapsulation of cytoplasmic cargos in a double membrane organelle called autophagosome and which culminates in the fusion of this compartment with the lytic vacuole. PI(3)P synthesis by the PI3K VPS34, which localizes to autophogosome in plant cells [41], is a key regulator of autophagosome formation across eukaryotes (Figure $3 a$ and $b$ ). Furthermore, both ESCRT and retromer mutants are defective in the autophagy process [29,36,42-44]. SNAREs are involved in the fusion of autophagosomes with the vacuole; it is therefore likely that some of the autophagy-related phenotypes in ESCRT and retromer mutants arise from mis-sorting of SNARE complexes [43]. In addition, FYVE1/FREE1 interacts with the PI(3)P-binding SRCHOMOLOGY3-CONTAING-PROTEINs SH3P2 and SH3P3, which localize in preautophagosomal structures in a VPS34-dependent manner [29,36]. SH3P2 binds AUTOPHAGY-RELATED-PROTEIN8 (ATG8) and the PI3K complex and is actively involved in the deformation of this membrane [41]. SH3P2/SH3P3 contain a BAR domain, which could facilitate membrane bending during autophagosome formation.

To conclude, $\mathrm{PI}(3) \mathrm{P}$ and $\mathrm{PI}(3,5) \mathrm{P} 2$ control protein sorting, including SNAREs, toward the vacuole or the TGN/EE, and may connect cortical microtubules with endosomal recycling and actin cytoskeleton with vacuole morphology.

\section{Phosphoinositides and polarized trafficking}

Phosphoinositides, in particular through the $\mathrm{PI} \rightarrow \mathrm{PI}(4) \mathrm{P} \rightarrow \mathrm{PI}(4,5) \mathrm{P}_{2}$ cascade (Figure 1c), regulate polarized exo- and endocytosis. In the following section, we will focus on their role in tip growing cells, which are highly polarized, but we will also use additional examples in other cell types when opportune.

\section{- PI(4,5)P2 targets endocytosis in pollen tube}

In tip growing cells (root hairs and pollen tubes) growth occurs via a massive polarized exocytosis of cell wall components at the growing tip and is counterbalanced by endocytosis occurring in subapical regions of the tube, forming a reversed-fountain flow of membranes (Figure 4a) [45]. Loss-of function mutants of phosphatidylinositol 4-phosphate 5-kinases (PIP5Ks) show low pollen germination rate, slow tube elongation, endocytic defects and reduced transmission through the male gametophyte [46,47]. In growing pollen tube, 
$\mathrm{PI}(4,5) \mathrm{P}_{2}$ localizes at the flank of apex, in a region with both endocytic and exocytic activities (Figure $4 \mathrm{a}$ and $\mathrm{b}$ ). This localization is maintained by a combination of local production of $\mathrm{PI}(4,5) \mathrm{P}_{2}$ by PIP5Ks, which localizes at the flank of apex [46-49] and degradation into DAG by PI-PLC, which localizes in the shank/subapical region (Figure $4 b$ and c) [50,51].

PIP5K6-OE enhances endocytosis, which results in PM invagination and the formation of several tip branches [48]. The expression of a clathrin dominant negative can rescue the PIP5K6-OE phenotype indicating that $\mathrm{PI}(4,5) \mathrm{P}_{2}$ synthesis regulates clathrin-mediated endocytosis [48]. A role of $\mathrm{PI}(4,5) \mathrm{P}_{2}$ in endocytosis in plants is further supported by the study of PIP5K1 and PIP5K2 in sporophytic tissues. PIP5K1 and PIP5K2 are auxin-induced genes that regulate clathrin membrane recruitment, endocytic trafficking and PIN polarity [3,52-54].

\section{- The exocyst is an anionic phospholipid effector involved in polarized secretion}

The exocyst complex tethers secretory vesicles to the PM, a prerequisite for subsequent membrane fusion [55]. The exocyst binds the PM through the SEC3 and EXO70 subunits, which both have lipid binding activities. In plants, SEC3 has a PH domain that binds $\mathrm{PI}(4,5) \mathrm{P}_{2}$ in vitro and colocalizes with $\mathrm{PI}(4,5) \mathrm{P}_{2}$ in vivo [56]. sec $3 a$ loss-of-functions show reduced pollen tube growth and fail to be transmitted through the male gametophyte [56]. The localization of SEC3 determines the direction of the growth and the site of pollen germination [56]. Furthermore, another anionic lipid, phosphatidic acid (PA), localizes in subapical PM regions of the pollen tube, which overlap only partially with tip-localized $\mathrm{PI}(4,5) \mathrm{P}_{2}$ [57]. In growing tobacco pollen tubes, two EXO70 isoforms (EXO70A1 and EXO70B1) overlap with $\mathrm{PI}(4,5) \mathrm{P}_{2}$ and PA markers, respectively (Figure 4b) [58]. It is possible that the exocyst complex targets specific PM sites through coincidence binding with several anionic phospholipids depending of the lipid binding properties of the EXO70 isoforms. The exocyst is involved in cell polarity establishment in many cell types, not just pollen tube. Additional examples of exocyst-based polarity include PINs and PEN3 polar localization [59-61], the establishment of an Ortmannian ring in trichromes [62], the patterning of xylem secondary cell wall [63], or the definition of the casparian strip domain [64]. In the later example, the localization of EXO70A1 in the casparian strip domain of the root endodermis nicely correlates with a local accumulation of $\mathrm{PI}(4,5) \mathrm{P} 2$, which is itself dependent on EXO70A1 activity [64].

\section{- A precise phosphoinositide patterning coordinates membrane trafficking during root hair morphogenesis}

Similar to pollen tubes, $\mathrm{PI}(4,5) \mathrm{P}_{2}$ is critical to coordinate membrane trafficking during root hair growth. PIP5K3 and PI(4,5) $\mathrm{P}_{2}$ localize at the tip of growing root hairs (Figure 4d) $[65,66]$. PIP5K3 is required for the polar localization of RHO-OF-PLANT2 (ROP2) and ROP6 during root hair initiation, which themselves coordinate endocytosis, exocytosis and cytoskeleton dynamics [67]. pip5k3 mutants have short root hairs, whereas PIP5K3 overexpression induces root hair deformation $[65,66]$. The localization of $\mathrm{PI}(4,5) \mathrm{P}_{2}$ at the tip of growing root hair is maintained by the action of AtSFH1/CAN OF WORMS (COW1), a SEC14 domain-containing protein that is localized at the tip region via direct interaction with $\mathrm{PI}(4,5) \mathrm{P}_{2}[68,69]$. Yeast SEC14 and AtSFH1/COW1 stimulate PI4K activity [70], suggesting that AtSFH1/COW1 might promote local PI(4)P synthesis at the root hair tip, which could be subsequently channeled to PIP5K3 for local PI(4,5)P2 synthesis (Figure 4d) [69]. AtSfh1 mutants have aberrant root hair morphology and show disperse secretory vesicles at their tip and disorganized actin and microtubule networks [68], highlighting the importance of precise phosphoinositide patterning for the coordination of membrane trafficking and cell polarity establishment. 
PI(4)P localizes in root hair subapical regions [71], as well as some intracellular compartments, which are likely TGN/EE (Figure 4c). PI4K $\beta 1-\beta 2$ and RHD4/AtSAC7, a PI(4)P phosphatase (Figure 3b), localize in RabA4b-positive TGN/EE at the tip of growing root hairs (Figure 4d) [11,27]. pi4k $\beta 1 / p i 4 k b \beta 2$ double and $r h d 4 / s a c 7$ single mutants have short bulged root hairs, with swollen TGN/EE, suggesting a critical role for PI(4)P in secretion [11,27,72]. In rhd4/sac7 mutants, PI(4)P accumulates in aberrant intracellular compartments that are likely TGN/EE [27,73]. It is possible that RHD4/AtSAC7 in TGN/EE erases incoming PI(4)P from the PM in order to maintain the PI(4)P gradient between these membranes [15]. However, it is still unclear how PI(4)P kinases and phosphatases cohabitate in the same compartment and/or whether they are localized in complementary subdomains of the TGN/EE (Figure 3b).

The overall consensus is that patterned phosphoinositides are needed to mark specific domains at the PM for localized endocytosis and exocytosis. In addition PI(4)P sorting activity at the TGN/EE is also involved in polarized trafficking toward the PM.

\section{Conclusions and future perspectives}

While most concepts linking phosphoinositides with membrane trafficking are conserved throughout eukaryotes, there are a number of emerging plant specific innovations. First, phosphoinositide subcellular localizations are different in plants and animals and one of the future challenges will be to decipher the mechanisms enabling phosphoinositide subcellular localization and maintenance in plants. A key point will be to further understand the tight coupling between the writer and eraser modules that generates phosphoinositide spatiotemporal patterns despite their constant dispersal by lateral diffusion and vesicular trafficking. Furthermore, compartment interactions at membrane contact sites are emerging as key regulators of lipid homeostasis and their importance in phosphoinositide synthesis has not yet been studied in plants. Second, it remains to be fully explored whether a bona fide lipid code exists for polarized trafficking in plants. One of the keys behind such code might be the presence of multiple EXO70 exocyst subunits that could define several PM domains, at least in part through specific interactions with various anionic lipids or combinations thereof. Finally, a plant specific pathway heavily relying on polarized membrane trafficking and not treated in this review is the establishment of the cell plate during cytokinesis. Several mutants defective in phosphoinositide metabolism harbor aberrant cell division phenotypes [72,74] and PIPs have distinctive localizations during cell division [15,20,22,73]. However, the exact roles of phosphoinositides in coordinating membrane traffic during cytokinesis are still poorly understood.

\section{Acknowledgments:}

We thank Matthieu Platre, Joseph Bareille, Laia Armengot, Mehdi Doumane, Alexandre Martinière-Delaunay, Marie-Cécile Caillaud, Christine Miège, Vincent Bayle and Yohann Boutté for critical comments on the manuscript. We apologize to researchers whose work could not be cited here due to space limitations. This work was supported by ERC no. 3363360-APPL under FP/2007-2013 to Y.J; and by a fellowship from ENS Lyon to L.C.N. 
References

* of special interest

** of outstanding interest

1. Jean S, Kiger AA: Coordination between RAB GTPase and phosphoinositide regulation and functions. Nat Rev Mol Cell Biol 2012, 13:463-470.

2. Platre MP, Jaillais Y: Guidelines for the Use of Protein Domains in Acidic Phospholipid Imaging. Methods Mol Biol 2016, 1376:175-194.

3. Armengot L, Marques-Bueno MM, Jaillais Y: Regulation of polar auxin transport by protein and lipid kinases. $J$ Exp Bot 2016, 67:4015-4037.

4. Posor Y, Eichhorn-Grunig M, Haucke V: Phosphoinositides in endocytosis. Biochim Biophys Acta 2015, 1851:794-804.

5. Lemmon MA: Membrane recognition by phospholipid-binding domains. Nat Rev Mol Cell Biol 2008, 9:99-111.

6. Phan NQ, Kim SJ, Bassham DC: Overexpression of Arabidopsis sorting nexin AtSNX2b inhibits endocytic trafficking to the vacuole. Mol Plant 2008, 1:961-976.

7. Pourcher M, Santambrogio M, Thazar N, Thierry AM, Fobis-Loisy I, Miege C, Jaillais Y, Gaude T: Analyses of sorting nexins reveal distinct retromer-subcomplex functions in development and protein sorting in Arabidopsis thaliana. Plant Cell 2010, 22:3980-3991.

8. Barberon M, Dubeaux G, Kolb C, Isono E, Zelazny E, Vert G: Polarization of IRONREGULATED TRANSPORTER 1 (IRT1) to the plant-soil interface plays crucial role in metal homeostasis. Proc Natl Acad Sci U S A 2014, 111:8293-8298.

9. Gao C, Luo M, Zhao Q, Yang R, Cui Y, Zeng Y, Xia J, Jiang L: A unique plant ESCRT component, FREE1, regulates multivesicular body protein sorting and plant growth. Curr Biol 2014, 24:2556-2563.

**10. Agorio A, Giraudat J, Bianchi MW, Marion J, Espagne C, Castaings L, Lelievre F, Curie C, Thomine S, Merlot S: Phosphatidylinositol 3-phosphate-binding protein AtPH1 controls the localization of the metal transporter NRAMP1 in Arabidopsis. Proc Natl Acad Sci U S A 2017.

This study shows for the first time that a $\mathrm{PH}$ domain-containing protein is a $\mathrm{PI}(3) \mathrm{P}$ effector in vivo and regulates the retrieval of the metal transporter NRAMP1 from late endosomes to the PM.

11. Preuss ML, Schmitz AJ, Thole JM, Bonner HK, Otegui MS, Nielsen E: A role for the RabA4b effector protein PI-4Kbeta1 in polarized expansion of root hair cells in Arabidopsis thaliana. J Cell Biol 2006, 172:991-998.

**12. Antignani V, Klocko AL, Bak G, Chandrasekaran SD, Dunivin T, Nielsen E: Recruitment of PLANT U-BOX13 and the PI4Kbeta1/beta2 phosphatidylinositol4 kinases by the small GTPase RabA4B plays important roles during salicylic acid-mediated plant defense signaling in Arabidopsis. Plant Cell 2015, 27:243-261.

This study reveals that PUB13, a known regulator of the pattern-recognition receptor FLS2 ubiquitination and trafficking, is targeted to the TGN/EE through the concomitent detection of $\mathrm{Rab} 4 \mathrm{Ab}$ and PI(4)P. The later interaction is mediated by an ARM domain, which constitutes a novel type of PI(4)P lipid binding domain. In addition, since RabA4b also recruits PI4K $\beta \mathrm{s}$, this study nicely illustrates the interdependent relationship between RabA4b and PI(4)P function at the TGN/EE.

13. Boutte Y, Moreau P: Modulation of endomembranes morphodynamics in the secretory/retrograde pathways depends on lipid diversity. Curr Opin Plant Biol 2014, 22:22-29. 
14. Platre MP, Jaillais Y: Anionic lipids and the maintenance of membrane electrostatics in eukaryotes. Plant Signal Behav 2017, 12:e1282022.

*15. Simon ML, Platre MP, Marques-Bueno MM, Armengot L, Stanislas T, Bayle V, Caillaud MC, Jaillais Y: A PtdIns(4)P-driven electrostatic field controls cell membrane identity and signalling in plants. Nat Plants 2016, 2:16089.

Using membrane surface charges sensors, this study reveals that the plant PM is highly electronegative compared to intracellular compartments. In addition, it shows that the localization of previously used PI(4)P biosensors were biased toward the TGN/EE because of coincident detection of the ARF1 GTPase. The use of novel ARF1-independent PI(4)P biosensors demonstrates that PI(4)P massively accumulates at the plant PM to drive the electrostatic signature of this membrane and the localization of proteins with polybasic stretch, such as the AGC kinase PINOID.

16. Jackson CL, Walch L, Verbavatz JM: Lipids and Their Trafficking: An Integral Part of Cellular Organization. Dev Cell 2016, 39:139-153.

17. Gallon M, Cullen PJ: Retromer and sorting nexins in endosomal sorting. Biochem Soc Trans 2015, 43:33-47.

*18. Dong R, Saheki Y, Swarup S, Lucast L, Harper JW, De Camilli P: Endosome-ER Contacts Control Actin Nucleation and Retromer Function through VAPDependent Regulation of PI4P. Cell 2016, 166:408-423.

$\mathrm{PI}(3) \mathrm{P}$ is considered a master regulator of early endosome functions in animals, in part by recruiting the retromer complex, a tubulation regulator. In this study, Dong et al., show that PI(4)P transiently accumulates at contact sites between early endosomes and the endoplasmic reticulum to affect actin dynamics by the WASH complex and drive tubule formation in conjunction with retromer activity.

19. Takenawa T: Phosphoinositide-binding interface proteins involved in shaping cell membranes. Proc Jpn Acad Ser B Phys Biol Sci 2010, 86:509-523.

20. Vermeer JE, van Leeuwen W, Tobena-Santamaria R, Laxalt AM, Jones DR, Divecha N, Gadella TW, Jr., Munnik T: Visualization of PtdIns3P dynamics in living plant cells. Plant $J$ 2006, 47:687-700.

21. Simon ML, Platre MP, Assil S, van Wijk R, Chen WY, Chory J, Dreux M, Munnik T, Jaillais Y: A multi-colour/multi-affinity marker set to visualize phosphoinositide dynamics in Arabidopsis. Plant J 2014, 77:322-337.

22. van Leeuwen W, Vermeer JE, Gadella TW, Jr., Munnik T: Visualization of phosphatidylinositol 4,5-bisphosphate in the plasma membrane of suspensioncultured tobacco BY-2 cells and whole Arabidopsis seedlings. Plant $J$ 2007, 52:1014-1026.

*23. Hirano T, Stecker K, Munnik T, Xu H, Sato MH: Visualization of phosphatidylinositol 3,5-bisphosphate dynamics by tandem ML1N-based fluorescent protein probe in Arabidopsis. Plant Cell Physiol 2017.

This study describes the characterization of transgenic Arabidopsis lines expressing a new fluorescent sensor for the rare lipid $\mathrm{PI}(3,5) \mathrm{P}_{2}$ and shows that this phosphoinositides localizes in late endosomes that are largely distinct from PI(3)P-containing endosomes.

24. Uemura T, Ueda T: Plant vacuolar trafficking driven by RAB and SNARE proteins. Curr Opin Plant Biol 2014, 22:116-121.

25. Scheuring D, Viotti C, Kruger F, Kunzl F, Sturm S, Bubeck J, Hillmer S, Frigerio L, Robinson DG, Pimpl P, et al.: Multivesicular bodies mature from the trans-Golgi network/early endosome in Arabidopsis. Plant Cell 2011, 23:3463-3481.

26. Singh MK, Kruger F, Beckmann H, Brumm S, Vermeer JE, Munnik T, Mayer U, Stierhof YD, Grefen $C$, Schumacher $K$, et al.: Protein delivery to vacuole requires SAND 
protein-dependent Rab GTPase conversion for MVB-vacuole fusion. Curr Biol 2014, 24:1383-1389.

27. Thole JM, Vermeer JE, Zhang Y, Gadella TW, Jr., Nielsen E: Root hair defective4 encodes a phosphatidylinositol-4-phosphate phosphatase required for proper root hair development in Arabidopsis thaliana. Plant Cell 2008, 20:381-395.

28. Belda-Palazon B, Rodriguez L, Fernandez MA, Castillo MC, Anderson EA, Gao C, Gonzalez-Guzman M, Peirats-Llobet M, Zhao Q, De Winne N, et al.: FYVE1/FREE1 Interacts with the PYL4 ABA Receptor and Mediates its Delivery to the Vacuolar Degradation Pathway. Plant Cell 2016.

*29. Kolb C, Nagel MK, Kalinowska K, Hagmann J, Ichikawa M, Anzenberger F, Alkofer A, Sato $\mathrm{MH}$, Braun $\mathrm{P}$, Isono $\mathrm{E}$ : FYVE1 is essential for vacuole biogenesis and intracellular trafficking in Arabidopsis. Plant Physiol 2015, 167:1361-1373.

Using a forward genetic screen, this study identifies FYVE1/FREE1 as an essential regulator of vacuole biogenesis. It shows that FYVE1 localizes on late endosomes, interacts with SH3P2 and SH3P3 and regulates ubiquitin-mediated degradation, vacuolar transport and autophagy.

30. Jaillais Y, Fobis-Loisy I, Miege C, Rollin C, Gaude T: AtSNX1 defines an endosome for auxin-carrier trafficking in Arabidopsis. Nature 2006, 443:106-109.

31. Jaillais Y, Santambrogio M, Rozier F, Fobis-Loisy I, Miege C, Gaude T: The retromer protein VPS29 links cell polarity and organ initiation in plants. Cell 2007, 130:1057-1070.

32. Kleine-Vehn J, Leitner J, Zwiewka M, Sauer M, Abas L, Luschnig C, Friml J: Differential degradation of PIN2 auxin efflux carrier by retromer-dependent vacuolar targeting. Proc Natl Acad Sci U S A 2008, 105:17812-17817.

33. Ambrose C, Ruan Y, Gardiner J, Tamblyn LM, Catching A, Kirik V, Marc J, Overall R, Wasteneys GO: CLASP interacts with sorting nexin 1 to link microtubules and auxin transport via PIN2 recycling in Arabidopsis thaliana. Dev Cell 2013, 24:649-659.

*34. Hirano T, Munnik T, Sato MH: Phosphatidylinositol 3-Phosphate 5-Kinase, FAB1/PIKfyve Kinase Mediates Endosome Maturation to Establish EndosomeCortical Microtubule Interaction in Arabidopsis. Plant Physiol 2015, 169:19611974.

This study establishes that the PI(3)P5 kinases from the Fab1 familly are involved in PIN2 trafficking during gravitropism and interact with the retromer component AtSNX1. Because AtSNX1 is known to interact with CLASP, the authors further established a link between endosome maturation and cortical microtubule function.

35. Zheng J, Han SW, Rodriguez-Welsh MF, Rojas-Pierce M: Homotypic vacuole fusion requires VTI11 and is regulated by phosphoinositides. Mol Plant 2014, 7:10261040.

*36. Gao C, Zhuang X, Cui Y, Fu X, He Y, Zhao Q, Zeng Y, Shen J, Luo M, Jiang L: Dual roles of an Arabidopsis ESCRT component FREE1 in regulating vacuolar protein transport and autophagic degradation. Proc Natl Acad Sci U S 2015, 112:1886-1891.

In addition to its role in vacuolar biogenesis, this study shows that the plant specific ESCRT component FYVE1/FREE1 interacts with SH3P2, a known regulator of autophagy and that fyvel/freel mutants accumulate autophagosomes in the cytosol that are not able to fuse with the tonoplast. Therefore, FYVE1/FREE1 has a dual function in vacuolar biogenesis and autophagy.

**37. Lofke C, Dunser K, Scheuring D, Kleine-Vehn J: Auxin regulates SNARE-dependent vacuolar morphology restricting cell size. Elife 2015, 4. 
This study shows that auxin controls vacuolar morphology to regulate cell size in the root. This auxin-mediated effect is regulated by the SNARE protein VTI11 in a PI4K-dependent manner, suggesting a role for PI(4)P in vacuolar sorting.

*38. Scheuring D, Lofke C, Kruger F, Kittelmann M, Eisa A, Hughes L, Smith RS, Hawes C, Schumacher K, Kleine-Vehn J: Actin-dependent vacuolar occupancy of the cell determines auxin-induced growth repression. Proc Natl Acad Sci U S 2016, 113:452-457.

Actin cytoskeleton is present in proximity of the tonoplast and is shown to regulate cell size in roots by controling vacuolar morphology in response to auxin. This auxin effect on actin cytoskeleton is partly abolished upon genetic and pharmacological interference with PI4K activity, suggesting that PI(4)P might regulate actin organization in proximity to the vacuole, through a yet unknown mechanism.

39. Novakova P, Hirsch S, Feraru E, Tejos R, van Wijk R, Viaene T, Heilmann M, Lerche J, De Rycke R, Feraru MI, et al.: SAC phosphoinositide phosphatases at the tonoplast mediate vacuolar function in Arabidopsis. Proc Natl Acad Sci U A 2014, 111:2818-2823.

40. Zhong R, Burk DH, Nairn CJ, Wood-Jones A, Morrison WH, 3rd, Ye ZH: Mutation of SAC1, an Arabidopsis SAC domain phosphoinositide phosphatase, causes alterations in cell morphogenesis, cell wall synthesis, and actin organization. Plant Cell 2005, 17:1449-1466.

41. Zhuang X, Wang H, Lam SK, Gao C, Wang X, Cai Y, Jiang L: A BAR-domain protein SH3P2, which binds to phosphatidylinositol 3-phosphate and ATG8, regulates autophagosome formation in Arabidopsis. Plant Cell 2013, 25:4596-4615.

42. Spitzer C, Li F, Buono R, Roschzttardtz H, Chung T, Zhang M, Osteryoung KW, Vierstra RD, Otegui MS: The endosomal protein CHARGED MULTIVESICULAR BODY PROTEIN1 regulates the autophagic turnover of plastids in Arabidopsis. Plant Cell 2015, 27:391-402.

43. Katsiarimpa A, Kalinowska K, Anzenberger F, Weis C, Ostertag M, Tsutsumi C, Schwechheimer $\mathrm{C}$, Brunner $\mathrm{F}$, Huckelhoven $\mathrm{R}$, Isono $\mathrm{E}$ : The deubiquitinating enzyme AMSH1 and the ESCRT-III subunit VPS2.1 are required for autophagic degradation in Arabidopsis. Plant Cell 2013, 25:2236-2252.

44. Munch D, Teh OK, Malinovsky FG, Liu Q, Vetukuri RR, El Kasmi F, Brodersen P, HaraNishimura I, Dangl JL, Petersen M, et al.: Retromer contributes to immunityassociated cell death in Arabidopsis. Plant Cell 2015, 27:463-479.

45. Grebnev G, Ntefidou M, Kost B: Secretion and Endocytosis in Pollen Tubes: Models of Tip Growth in the Spot Light. Front Plant Sci 2017, 8:154.

46. Ischebeck T, Stenzel I, Heilmann I: Type B phosphatidylinositol-4-phosphate 5-kinases mediate Arabidopsis and Nicotiana tabacum pollen tube growth by regulating apical pectin secretion. Plant Cell 2008, 20:3312-3330.

47. Sousa E, Kost B, Malho R: Arabidopsis phosphatidylinositol-4-monophosphate 5kinase 4 regulates pollen tube growth and polarity by modulating membrane recycling. Plant Cell 2008, 20:3050-3064.

48. Zhao Y, Yan A, Feijo JA, Furutani M, Takenawa T, Hwang I, Fu Y, Yang Z: Phosphoinositides regulate clathrin-dependent endocytosis at the tip of pollen tubes in Arabidopsis and tobacco. Plant Cell 2010, 22:4031-4044.

49. Ischebeck T, Stenzel I, Hempel F, Jin X, Mosblech A, Heilmann I: Phosphatidylinositol4,5-bisphosphate influences Nt-Rac5-mediated cell expansion in pollen tubes of Nicotiana tabacum. Plant $J$ 2011, 65:453-468. 
50. Helling D, Possart A, Cottier S, Klahre U, Kost B: Pollen tube tip growth depends on plasma membrane polarization mediated by tobacco PLC3 activity and endocytic membrane recycling. Plant Cell 2006, 18:3519-3534.

51. Dowd PE, Coursol S, Skirpan AL, Kao TH, Gilroy S: Petunia phospholipase c1 is involved in pollen tube growth. Plant Cell 2006, 18:1438-1453.

52. Mei Y, Jia WJ, Chu YJ, Xue HW: Arabidopsis phosphatidylinositol monophosphate 5kinase 2 is involved in root gravitropism through regulation of polar auxin transport by affecting the cycling of PIN proteins. Cell Res 2012, 22:581-597.

53. Ischebeck T, Werner S, Krishnamoorthy P, Lerche J, Meijon M, Stenzel I, Lofke C, Wiessner T, Im YJ, Perera IY, et al.: Phosphatidylinositol 4,5-bisphosphate influences PIN polarization by controlling clathrin-mediated membrane trafficking in Arabidopsis. Plant Cell 2013, 25:4894-4911.

54. Tejos R, Sauer M, Vanneste S, Palacios-Gomez M, Li H, Heilmann M, van Wijk R, Vermeer JE, Heilmann I, Munnik T, et al.: Bipolar Plasma Membrane Distribution of Phosphoinositides and Their Requirement for Auxin-Mediated Cell Polarity and Patterning in Arabidopsis. Plant Cell 2014, 26:2114-2128.

55. Vukasinovic N, Zarsky V: Tethering Complexes in the Arabidopsis Endomembrane System. Front Cell Dev Biol 2016, 4:46.

**56. Bloch D, Pleskot R, Pejchar P, Potocky M, Trpkosova P, Cwiklik L, Vukasinovic N, Sternberg H, Yalovsky S, Zarsky V: Exocyst SEC3 and Phosphoinositides Define Sites of Exocytosis in Pollen Tube Initiation and Growth. Plant Physiol 2016, 172:980-1002.

This study shows that the SEC3a exocyst subunit binds in vitro to $\mathrm{PI}(4,5) \mathrm{P} 2$ via its $\mathrm{N}$-terminal $\mathrm{PH}$ domain and colocalize in vivo with this lipid in tobacco pollen tube, providing direct experimental evidence for a link between the exocyst activity and $\mathrm{PI}(4,5) \mathrm{P}_{2}$ in plants.

Furthermore, using timelapse microscopy approaches, the authors elegantly demonstrate that SEC3a localization is different in growing pollen tube that undergo steady or oscilatory growth; suggesting that phosphoinositide localization may be different during these two modes of growth and prompting further evaluation of anionic lipids localization during tip growth.

57. Potocky M, Pleskot R, Pejchar P, Vitale N, Kost B, Zarsky V: Live-cell imaging of phosphatidic acid dynamics in pollen tubes visualized by Spo20p-derived biosensor. New Phytol 2014, 203:483-494.

**58. Sekeres J, Pejchar P, Santrucek J, Vukasinovic N, Zarsky V, Potocky M: Analysis of Exocyst Subunit EXO70 Family Reveals Distinct Membrane Polar Domains in Tobacco Pollen Tubes. Plant Physiol 2017, 173:1659-1675.

This paper shows that multiple EXO70 subunits localize to various subcellular localizations in growing tobacco pollen tubes, suggesting that different EXO70 subunits might target

exocytosis at various locations within the same cell. In particular, it shows that EXO70A1 and EXO70B1 partially overlap with $\mathrm{PA}$ and $\mathrm{PI}(4,5) \mathrm{P}_{2}$ biosensors, respectively, raising the possibility that these EXO70 subunits might have different anionic phospholipid binding properties for membrane targeting.

59. Drdova EJ, Synek L, Pecenkova T, Hala M, Kulich I, Fowler JE, Murphy AS, Zarsky V: The exocyst complex contributes to PIN auxin efflux carrier recycling and polar auxin transport in Arabidopsis. Plant $J$ 2013, 73:709-719.

60. Tan X, Feng Y, Liu Y, Bao Y: Mutations in exocyst complex subunit SEC6 gene impaired polar auxin transport and PIN protein recycling in Arabidopsis primary root. Plant Sci 2016, 250:97-104. 
61. Mao H, Nakamura M, Viotti C, Grebe M: A Framework for Lateral Membrane Trafficking and Polar Tethering of the PEN3 ATP-Binding Cassette Transporter. Plant Physiol 2016, 172:2245-2260.

62. Kulich I, Vojtikova Z, Glanc M, Ortmannova J, Rasmann S, Zarsky V: Cell wall maturation of Arabidopsis trichomes is dependent on exocyst subunit EXO70H4 and involves callose deposition. Plant Physiol 2015, 168:120-131.

63. Vukasinovic N, Oda Y, Pejchar P, Synek L, Pecenkova T, Rawat A, Sekeres J, Potocky $\mathrm{M}$, Zarsky V: Microtubule-dependent targeting of the exocyst complex is necessary for xylem development in Arabidopsis. New Phytol 2017, 213:10521067.

**64. Kalmbach L, Hematy K, De Bellis D, Barberon M, Fujita S, Ursache R, Daraspe J, Geldner N: Transient cell-specific EXO70A1 activity in the CASP domain and Casparian strip localization. Nat Plants 2017, 3:17058.

The exo70al mutants shows delocalization of casparian strip (CS) proteins (such as CASP1 or ESB1) out of the central domain (CD) into PM microdomains, suggesting a critical role of the exocyst complex for the polar targeting of these proteins. In differentiating root endodermal cells, EXO70A1 and other exocyst subunits localize to the $\mathrm{CD}$, a localization that correlates with the localization of $\mathrm{PI}(4,5) \mathrm{P}_{2}$. This correlation suggests that $\mathrm{PI}(4,5) \mathrm{P}_{2}$ might control EXO70A1 targeting to the CD. Interestingly, EXO70A1 activity is itself required for $\mathrm{PI}(4,5) \mathrm{P}_{2}$ accumulation into the $\mathrm{CD}$, suggesting a possible interdependent targeting mechanism between the exocyst and phosphoinositides in this cell type.

65. Kusano H, Testerink C, Vermeer JE, Tsuge T, Shimada H, Oka A, Munnik T, Aoyama T: The Arabidopsis Phosphatidylinositol Phosphate 5-Kinase PIP5K3 is a key regulator of root hair tip growth. Plant Cell 2008, 20:367-380.

66. Stenzel I, Ischebeck T, Konig S, Holubowska A, Sporysz M, Hause B, Heilmann I: The type $B$ phosphatidylinositol-4-phosphate 5-kinase 3 is essential for root hair formation in Arabidopsis thaliana. Plant Cell 2008, 20:124-141.

**67. Stanislas T, Huser A, Barbosa IC, Kiefer CS, Brackmann K, Pietra S, Gustavsson A, Zourelidou M, Schwechheimer C, Grebe M: Arabidopsis D6PK is a lipid domaindependent mediator of root epidermal planar polarity. Nat Plants 2015, 1:15162.

The site of root hair initiation is highly polarized. This study shows that a specialized membrane domain at the root hair initiation site is enriched in Rho GTPases (ROP2 and ROP6), dynamins (DRP1A and DRP2B), the PI(4,5)P2-producing enzyme PIP5K3 and sterol. These proteins and lipids are required for the positioning of this membrane domain and D6PK localization, suggesting an interdependent relationship between lipid signals and membrane trafficking regulators for the recruitment of signaling kinases.

68. Vincent P, Chua M, Nogue F, Fairbrother A, Mekeel H, Xu Y, Allen N, Bibikova TN, Gilroy S, Bankaitis VA: A Sec14p-nodulin domain phosphatidylinositol transfer protein polarizes membrane growth of Arabidopsis thaliana root hairs. $J$ Cell Biol 2005, 168:801-812.

*69. Ghosh R, de Campos MK, Huang J, Huh SK, Orlowski A, Yang Y, Tripathi A, Nile A, Lee $\mathrm{HC}$, Dynowski $\mathrm{M}$, et al.: Sec14-nodulin proteins and the patterning of phosphoinositide landmarks for developmental control of membrane morphogenesis. Mol Biol Cell 2015, 26:1764-1781.

This paper reveals that AtSFH1 binds specifically to PI $(4,5) \mathrm{P}_{2}$ through a Lysine-rich peptide at the C-terminal end of its nodulin domain. In turn PI(4,5) $\mathrm{P}_{2}$-binding targets AtSFH1 at the tip of growing root hair and is required for $\mathrm{PI}(4,5) \mathrm{P}_{2}$ patterning, suggesting that this $\mathrm{Sec} 14$ nodulin domain protein might control the lateral organization of $\mathrm{PI}(4,5) \mathrm{P}_{2}$ to regulate polarized tip growth. 
70. Huang J, Ghosh R, Tripathi A, Lonnfors M, Somerharju P, Bankaitis VA: Two-ligand priming mechanism for potentiated phosphoinositide synthesis is an evolutionarily conserved feature of Sec14-like phosphatidylinositol and phosphatidylcholine exchange proteins. Mol Biol Cell 2016, 27:2317-2330.

71. Yoo CM, Quan L, Cannon AE, Wen J, Blancaflor EB: AGD1, a class 1 ARF-GAP, acts in common signaling pathways with phosphoinositide metabolism and the actin cytoskeleton in controlling Arabidopsis root hair polarity. Plant $J$ 2012, 69:10641076.

72. Kang BH, Nielsen E, Preuss ML, Mastronarde D, Staehelin LA: Electron tomography of RabA4b- and PI-4Kbeta1-labeled trans Golgi network compartments in Arabidopsis. Traffic 2011, 12:313-329.

73. Vermeer JE, Thole JM, Goedhart J, Nielsen E, Munnik T, Gadella TW, Jr.: Imaging phosphatidylinositol 4-phosphate dynamics in living plant cells. Plant $J 2009$, 57:356-372.

74. Vollmer AH, Youssef NN, DeWald DB: Unique cell wall abnormalities in the putative phosphoinositide phosphatase mutant AtSAC9. Planta 2011, 234:993-1005.

75. Naramoto S, Sawa S, Koizumi K, Uemura T, Ueda T, Friml J, Nakano A, Fukuda H: Phosphoinositide-dependent regulation of VAN3 ARF-GAP localization and activity essential for vascular tissue continuity in plants. Development 2009, 136:1529-1538.

76. Barbosa IC, Shikata H, Zourelidou M, Heilmann M, Heilmann I, Schwechheimer C: Phospholipid composition and a polybasic motif determine D6 PROTEIN KINASE polar association with the plasma membrane and tropic responses. Development 2016, 143:4687-4700.

77. Ebine K, Inoue T, Ito J, Ito E, Uemura T, Goh T, Abe H, Sato K, Nakano A, Ueda T: Plant vacuolar trafficking occurs through distinctly regulated pathways. Curr Biol 2014, 24:1375-1382.

78. von Wangenheim D, Rosero A, Komis G, Samajova O, Ovecka M, Voigt B, Samaj J: Endosomal Interactions during Root Hair Growth. Front Plant Sci 2015, 6:1262.

79. Vermeer JE, Wijk RV, Goedhart J, Geldner N, Chory J, Gadella TW, Munnik T: In Vivo Imaging of Diacylglycerol at the Cytoplasmic Leaflet of Plant Membranes. Plant Cell Physiol 2017. 


\section{Figure legends:}

Figure 1. The phosphoinositide code and interdependent relationship with small GTPases. a) Schematic representation of phosphoinositides. Possible phosphorylation on the third, forth and/or fifth position on the inositol ring are indicated by arrows. Note that PI kinases or phosphatases act on these phosphorylation, while PI-PLC cut PIs below the phosphate group to release DAG and soluble inositol. Phosphorylations are represented by orange circles. b) Representation of the lipid code hypothesis embodied by the presence of writer, eraser and reader modules and the phosphoinositide cycle. c) The two phosphoinositide cascades in plants. Generic enzyme names are written in capital letter, example of Arabidopsis proteins with proven enzymatic activities and roles in membrane trafficking are indicated in italic. d) Schematic representation of Rab-regulated phosphoinositide phosphorylation or dephosphorylation. e) Schematic representation of phosphoinositide-regulated small GTPase activation or deactivation. f) Schematic representation of effector recruitment by coincidence binding of an activated small GTPase and a phosphoinositide. g) Schematic representation of phosphoinositide-regulated phosphoinositide phosphorylation or dephosphorylation. d-g) Plant examples are indicated in italics, and have been described in the following papers: PI4Kb [11], VAN3 [75], PUB13 [12], FAB1A-B/PIKfyve [34]. DAG, diacylglycerol; IP2, inositol-1-4-biphosphate; IP3, inositol-1-4-5-triphosphate; PI-PLC, phosphoinositide-dependent phospholipase C; Ptase, phosphatase; PIP, phosphatidylinositol monophosphate; PIP2, phosphatidylinositol bisphosphate; LBD, lipid binding domain; SAC, SUPPRESSOR OF ACTIN; RHD4, ROOT HAIR DEFECTIVE4; PI(3)P, phosphatidylinositol-(3)-phosphate; PI(4)P, phosphatidylinositol-(4)-phosphate, $\mathrm{PI}(3,5) \mathrm{P}_{2}$, phosphatidylinositol-(3-5)-bisphosphate; $\mathrm{PI}(4,5) \mathrm{P} 2$, phosphatidylinositol-(4-5)-bisphosphate; PI(3)P5K, phosphatidylinositol-(3)phosphate 5-kinase; PI(4)P5K, phosphatidylinositol-(4)-phosphate 5-kinase; PI4K, phosphatidylinositol 4-kinase; PI, phosphoinositides; TGN, trans-Golgi Network; EE, Early Endosomes; LE, Late endosomes; MVB, multivesicular bodies; GAP, GTPase Activating Protein; GEF, GTPase Exchange Factor; VAN3, VASCULAR NETWORK3; PUB13, PLANT U-BOX13; PIKfyve, PHOSPHOINOSITIDE KINASE FYVE FINGER CONTAINING.

Figure 2. Influence of phosphoinositides on physicochemical membrane parameters. a) Membrane physicochemical properties may be conceptualized in three main categories including lipid packing defects, curvature and electrostatics. The latter two are directly influenced by phosphoinositides. b) Schematic representation of the plant electrostatic territory, which includes membranes with varying degree of negative surface charges, the highest being at the PM. The red triangle indicates the concentration gradient of PI(4)P between the PM and TGN/EE and that controls the high PM electrostatic field. c) Specific recruitment of proteins with polybasic/hydrophobic regions to the PM largely through $\mathrm{PI}(4) \mathrm{P}$ driven electrostatics. Note that PA and $\mathrm{PI}(4,5) \mathrm{P}_{2}$ are also involved in D6PK membrane association [76]. d) Schematic representation of protein recruitment by coincidence detection of both curvature and electrostatics (e.g. proteins containing BAR domains or specialized amphipathic helices from the +ALPS class $[5,16,17])$. e) Schematic representation of the importance of phosphoinositides in vesicle formation through the coordination of actin polymerization, and recruitment/activation of membrane deformation components, including coat proteins and the scission machinery. Note that the example shown in panel e) relates to clathrin-mediated endocytosis, but similar concepts may be applied for the formation of other clathrin-coated vesicles, for example at the TGN. f) Schematic representation of the importance of phosphoinositides in tubule formation through the coordination of actin 
polymerization, and the membrane tubulation machinery. Note that the examples shown in $d$ ) to e) have not been formally demonstrated in plants even tough proteins containing similar domains are found in plant genomes and the general concepts are likely applicable to plant endomembrane trafficking. LBD, Lipid Binding Domain; SNX, SORTING NEXIN; BAR, Bin Amphiphysinn Rvs; +ALPS, +amphipathic lipid-packing sensor; PX, PHOX Homology; LE, Late Endosomes; MVB, MultiVesicular Bodies; PM, plasma membrane; PI, phosphoinositides; N-WASP, NEURAL WISKOTT-ALDRICH SYNDROME PROTEIN; WASH, WASP AND SCAR HOMOLOGUE; AP2, ADAPTOR-COMPLEX2; D6PK, D6 PROTEIN KINASE. Negative charges carried by anionic phospholipids are represented by black circles; cationic residues by red circles; aromatic/hydrophobic residues by purple circles; phosphorylation by orange circles. $\mathrm{PI}(4) \mathrm{P}$ distribution is shown in red, $\mathrm{PI}(4,5) \mathrm{P}_{2}$ in green, $\mathrm{PI}(3) \mathrm{P}$ in orange, actin polymerization factors in purple, membrane coat in blue and scission machinery in pink. All lipid localizations shown are for the cytosolic membrane leaflet only.

Figure 3: Subcellular map of phosphoinositide localization in Arabidopsis root epidermis. a) Schematic representation of endomembrane trafficking pathways. CCVs emanating from the TGN, and likely involving the AP3 clathrin adaptor, define a vacuolar trafficking pathway independent on canonical RabF-containing LE/MVB [77]. b) Writer and eraser modules with known localization and likely contributing to phosphoinositide patterning. c) Hypothetical model for ESCRT and retromer-mediated sorting during TGN/EE to LE/MVB maturation. Canonical markers of the TGN/EE (VHA-al and RabAs) and LE/MVB (RabFs, e.g. ARA7) are indicated in italics. Note that maturating TGN/EE displays both markers, suggesting the existence of transient hybrid organelles, where protein sorting might occur. The existence of such maturating TGN/EE, that contains RabF/PI(3)P as well as VHA-a1 markers was proposed in [26]. PI(3)P distribution is shown in orange; PI(4)P in red; $\mathrm{PI}(4,5) \mathrm{P}_{2}$ in green and $\mathrm{PI}(3,5) \mathrm{P}_{2}$ in blue. Arrows represent trafficking pathways between compartments. PM, Plasma Membrane; TGN, trans-Golgi Network; EE, Early Endosomes; LE, Late Endosomes; MVB, MultiVesicular Bodies; CCV, Clathrin Coated Vesicle; SV, Secretory vesicle. Triangles indicate concentration gradient of PI(4)P between the PM and TGN/EE and PI(3)P between LE/MVB and tonoplast. PI(3)P, phosphatidylinositol-(3)phosphate; PI(4)P, phosphatidylinositol-(4)-phosphate, $\mathrm{PI}(3,5) \mathrm{P}$, phosphatidylinositol-(3-5)bisphosphate; PI(4,5)P2, phosphatidylinositol-(4-5)-bisphosphate. SAC, SUPPRESSOR OF ACTIN; PI4K, phosphatidylinositol 4-kinase; PIP5K, phosphatidylinositol-(4)-phosphate 5kinase; PI-PLC, phosphoinositide-dependent phospholipase C; AP3, ADAPTOR PROTEIN 3; VPS34, VACUOLAR PROTEIN SORTING34, ESCRT, ENDOSOMAL SORTING COMPLEX REQUIRED FOR TRANSPORT. All lipid localizations shown are for the cytosolic membrane leaflet only.

Figure 4: Subcellular maps of phosphoinositide localization in tip growing cells. a) Schematic representation of the organization of tip growing cells. b) and d) are an attempt to draw maps of lipid localization in pollen tubes and root hairs, respectively. It is important to be cautious with such maps, since there is no consensus across different studies for the localization of PIP metabolic enzymes and PIP sensors in these systems. This is likely because anionic lipids localizations are highly dynamic in tip growing cells and vary with the mode of growth (i.e. oscillatory or steady growth, see for example Ref [56]). As such, snapshot images are unlikely to represent a full account of lipid/protein localizations. The localizations presented in figure 4 are personal interpretations, which should be further studied using quantitative time-lapse imaging. c) Conceptual model for the acquisition and maintenance of patterned phosphoinositide membrane domains/organelles. Polarized 
phosphoinositide kinases locally produce a given PI species. Phospholipases or phosphatases with complementary localization to the writer modules allow the establishment of sharp phosphoinositide boundaries by removing incoming PIs that escaped the polar domains either by lateral diffusion or vesicular trafficking. PI(3)P distribution is shown in orange (localization in root hair studied in [78]); $\mathrm{PI}(4) \mathrm{P}$ in red; $\mathrm{PI}(4,5) \mathrm{P}_{2}$ in green, $\mathrm{PI}(3,5) \mathrm{P}_{2}$ in blue, $\mathrm{PA}$ in pink and DAG in purple (localization in pollen tube studied in [50] and in root hair in [79]). Chevron-shaped arrows represent trafficking pathways between compartments; triangle-shaped arrows indicate activation. Exo, exocytosis; endo, endocytosis; PM, Plasma Membrane; TGN, trans-Golgi Network; EE, Early Endosomes; LE, Late Endosomes; MVB, MultiVesicular Bodies; CCV, Clathrin Coated Vesicle; SV, Secretory vesicle. Name of enzymes/proteins involved in phosphoinositides metabolism and/or trafficking are in italic next to the compartment in which they reside. PI(3)P, phosphatidylinositol-(3)-phosphate; PI(4)P, phosphatidylinositol-(4)-phosphate, PI(3,5) $\mathrm{P}_{2}$, phosphatidylinositol-(3-5)bisphosphate; PI(4,5)P2, phosphatidylinositol-(4-5)-bisphosphate; RHD4, ROOT HAIR DEFCTIVE4; SAC, SUPPRESSOR OF ACTIN; COW, CAN OF WORMS; ROP, RHO OF PLANT; PI4K, phosphatidylinositol 4-kinase; PIP5K, phosphatidylinositol-(4)-phosphate 5kinase; PI-PLC, phosphoinositide-dependent phospholipase C; DAG, Diacylglycerol; PA, phosphatidic acid. All lipid localizations shown are for the cytosolic membrane leaflet only. 


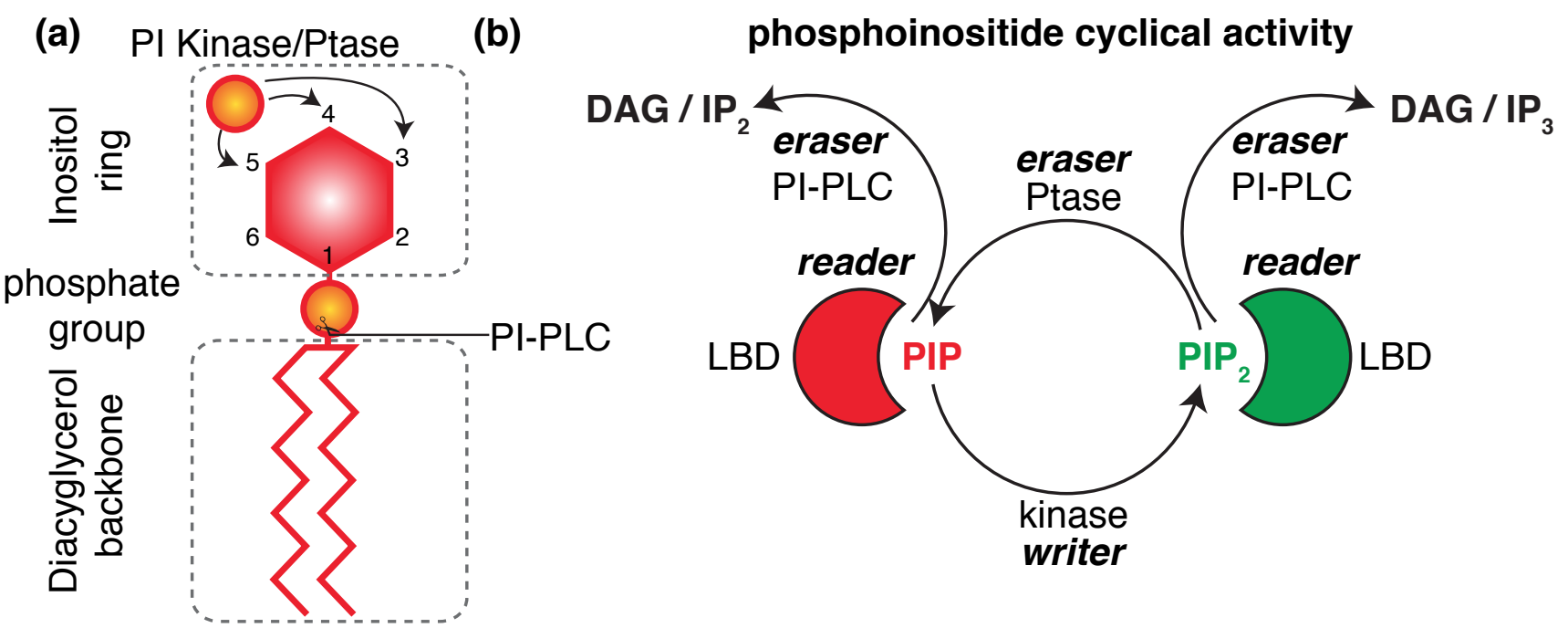

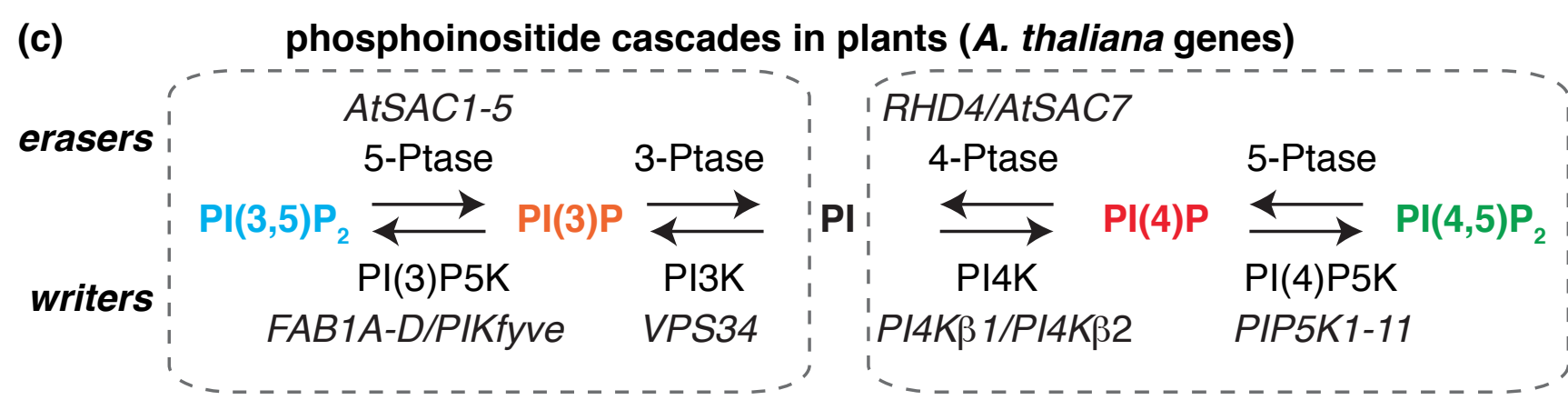

PI cascade focused on trafficking to or PI cascade focused on trafficking to or away from late endosomes away from early endosomes

(d) PI regulation by RAB

(e)

GTPase regulation by PI

writer/eraser kinase / phosphatase PIP

recruitment (de)phosphorylation

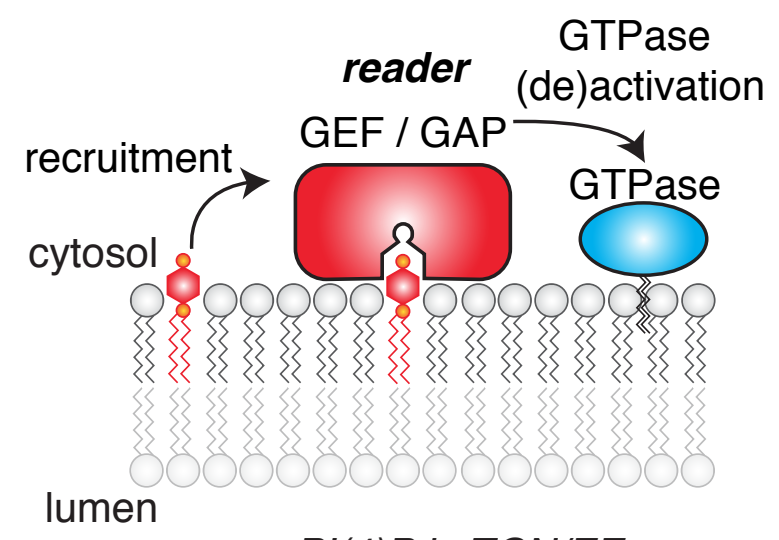

e.g. RabA4b in TGN/EE

lumen

recruits $P I 4 K \beta$ s to produce $P I(4) P$

recruits and activates the ARF-GAP VAN3

(f) coincidence detection

(g)

PI regulation by $\mathbf{P I}$

reader

effector recruitment

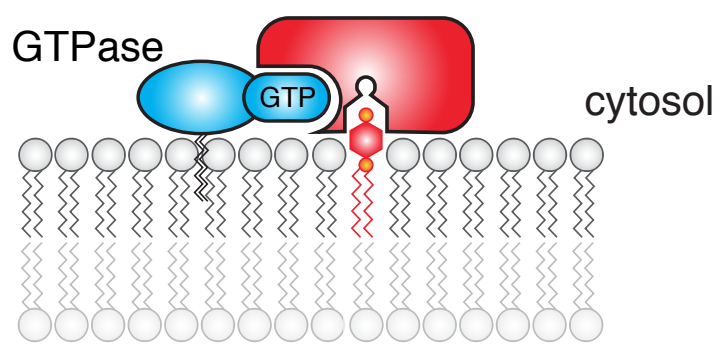

Iumen

e.g. PUB13 is recruited to TGN/EE by coincidence binding of RabA4b and PI(4)P

writer/eraser kinase / PIP

\& reader phosphatase (de)phosphorylation

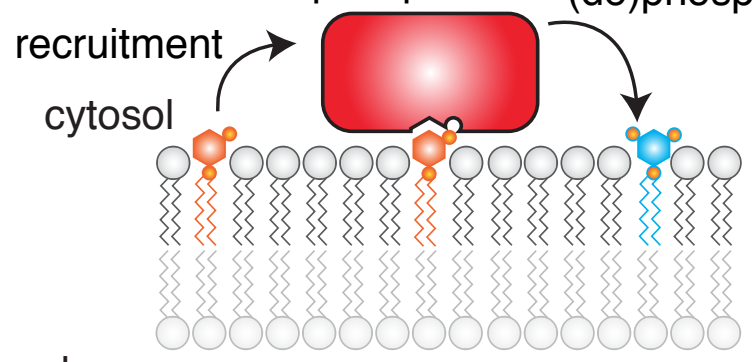

lumen

e.g. FAB1A-B/PIKfyve are PI(3)P5Ks

recruited to $L E / M V B$ by their substrate $P I(3) P$ 
(a)

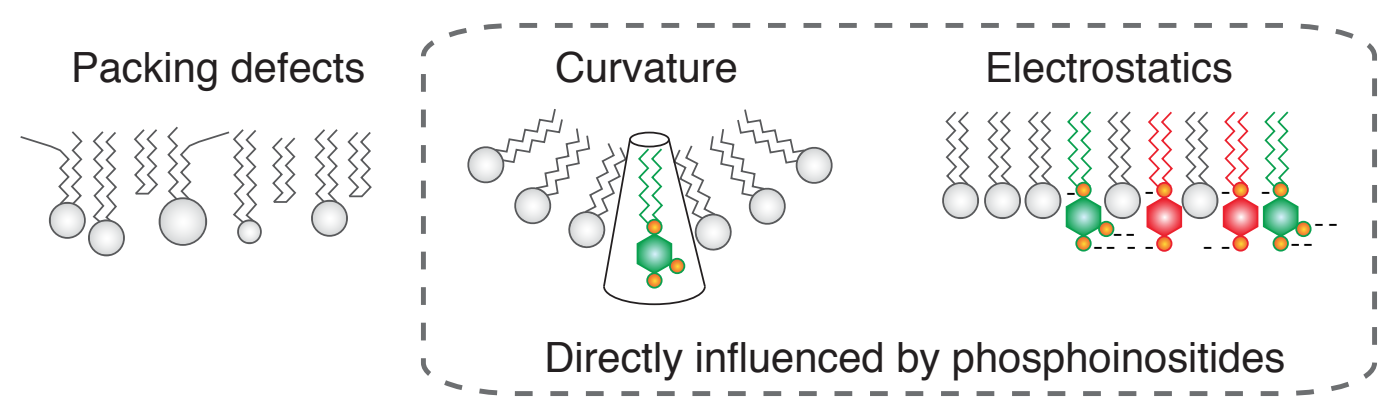

(b) electrostatic territoty in plants

(c) PM targeting by electrostatics

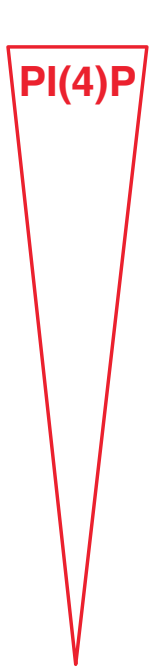

highly electronegative

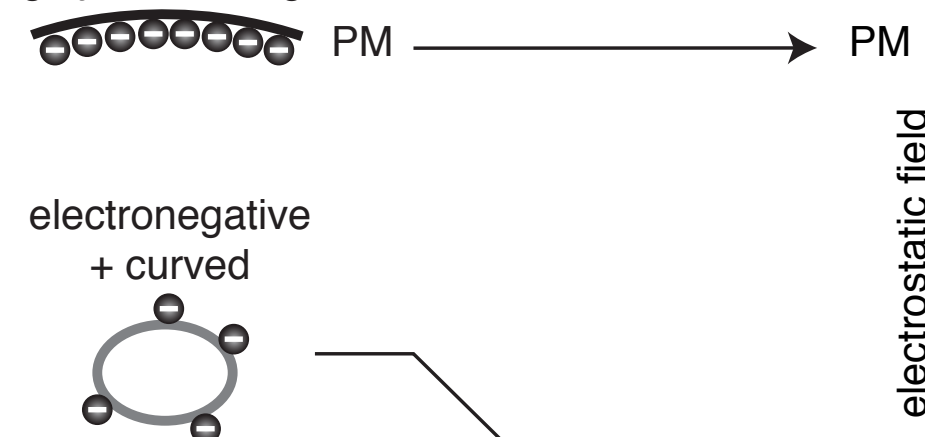

$\mathrm{PM}$

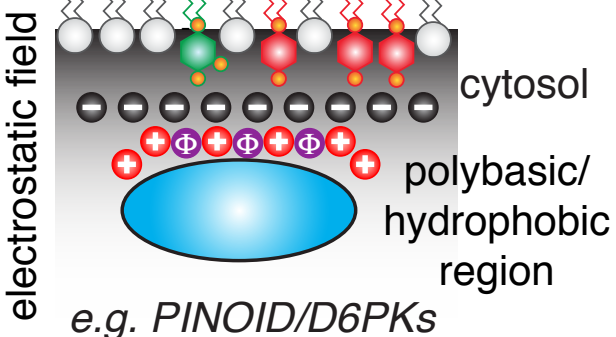

intracellular compartments

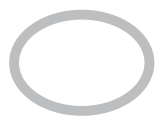

neutral + curved (d) coincidence detection of curvature and electrostatics

cytosol<smiles>O=c1cccccc1</smiles><smiles></smiles>

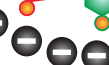

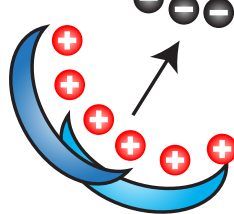

BAR domain (f)

PI-mediated tubule formation (e.g. retromer-mediated tubulation)

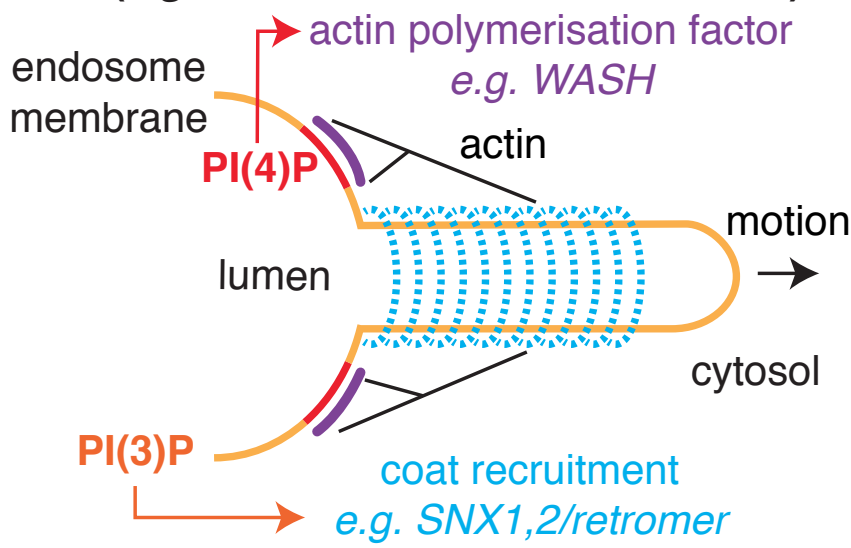


(a)

PM $\frac{\text { cell wall }}{\text { cytosol }}$
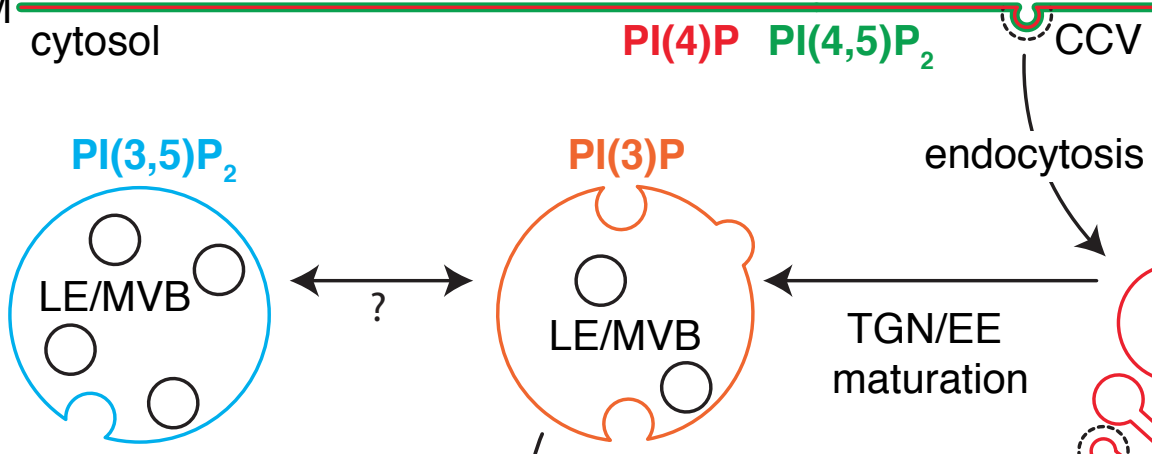

$\mathrm{PI}(3) \mathrm{P}$

endocytosis
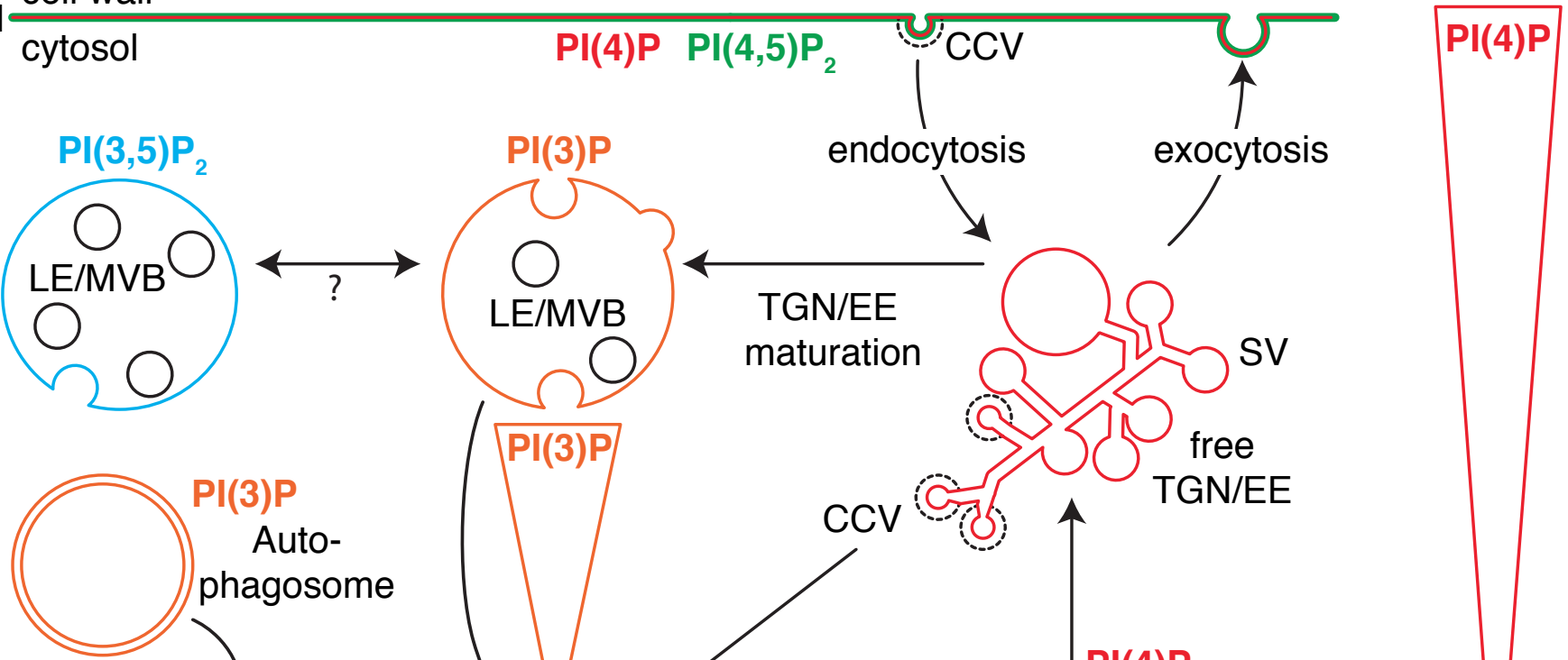

$\mathrm{PI}(3) \mathrm{P}$

Autophagosome tonoplast $\mathrm{PI}(3) \mathrm{P}$
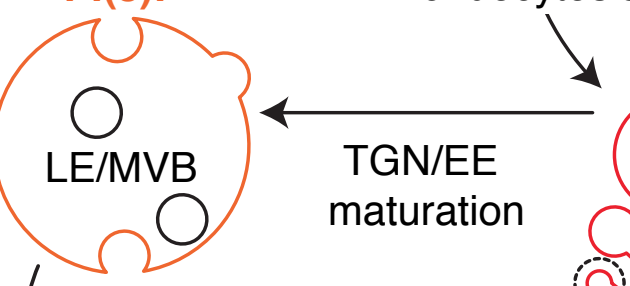
exocytosis maturation

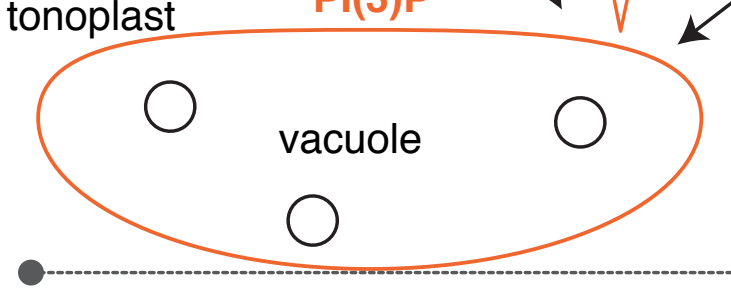

$\mathrm{PI}(3) \mathrm{P} \quad \mathrm{PI}(3,5) \mathrm{P}_{2}$

trafficking and sorting centered on late endosomes

(b)

$$
\text { (b) }
$$

\begin{tabular}{|c|c|c|}
\hline compartment & writer: substrate $>$ product & eraser: substrate $>$ product \\
\hline Golgi & & 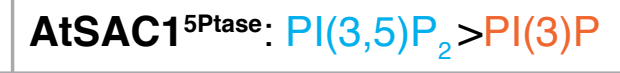 \\
\hline TGN/EE & PI4K $\beta 1-P I 4 K \beta 2: \mathrm{Pl}>\mathrm{PI}(4) \mathrm{P}$ & RHD4/AtSAC7 ${ }^{4 \text { Ptase }: ~} \mathrm{Pl}(4) \mathrm{P}>\mathrm{PI}$ \\
\hline PM & PIP5K: $\mathrm{Pl}(4) \mathrm{P}>\mathrm{PI}(4,5) \mathrm{P}_{2}$ & PI-PLC: $\mathrm{PI}(4) \mathrm{P} \quad \& \quad \mathrm{PI}(4,5) \mathrm{P}_{2}$ \\
\hline LE/MVB & VPS34 ${ }^{\mathrm{PI} \mid 3 K}: \mathrm{Pl}>\mathrm{PI}(3) \mathrm{P} ; \mathbf{F A B 1} 1^{\mathrm{PIPFK}}: \mathrm{PI}(3) \mathrm{P}>\mathrm{PI}(3,5) \mathrm{P}_{2}$ & \\
\hline Vacuole & & AtSAC2-5 5Ptase: $\mathrm{PI}(3,5) \mathrm{P}_{2}>\mathrm{PI}(3) \mathrm{P}$ \\
\hline Autophagosome & VPS344 ${ }^{\mathrm{PI} K}: \mathrm{PI}>\mathrm{PI}(3) \mathrm{P}$ & \\
\hline
\end{tabular}

(c) hypothetical model of TGN/EE to LE/MVB maturation via PI(4)P-to- $\mathrm{PI}(3) \mathrm{P}$ convertion

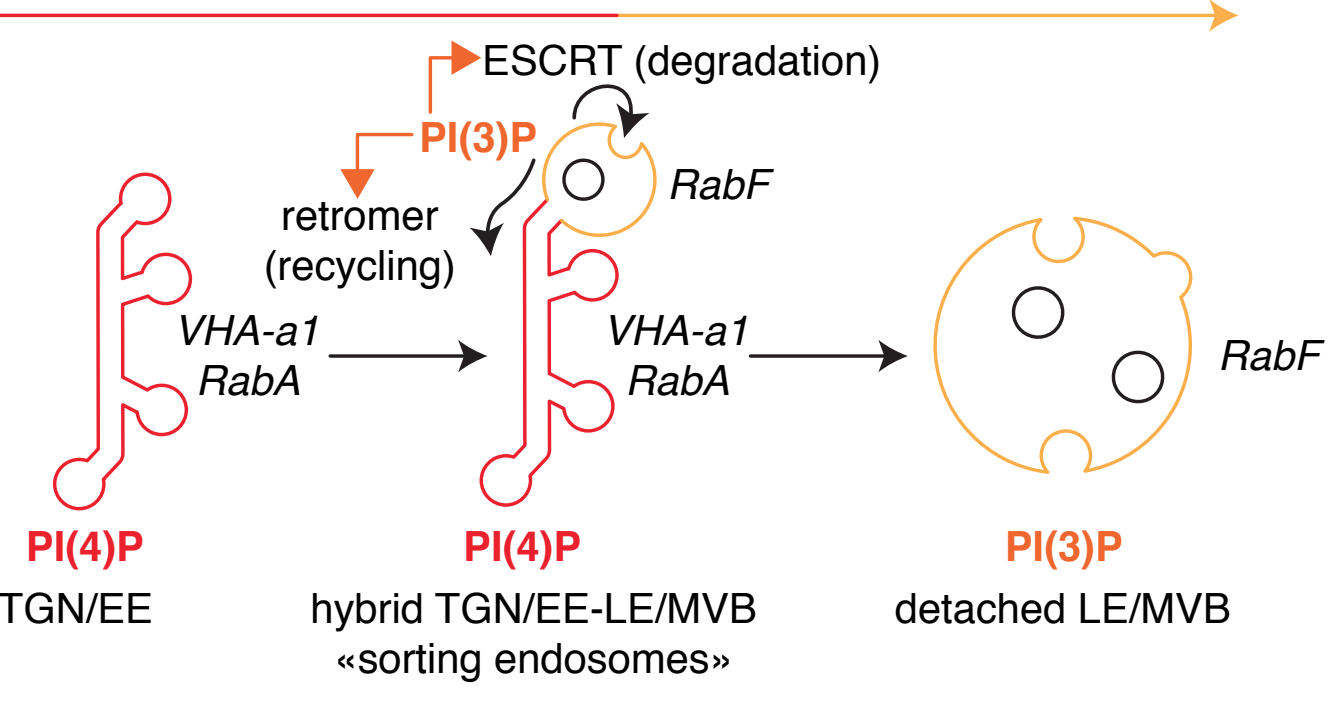


(a) tip growth glossary

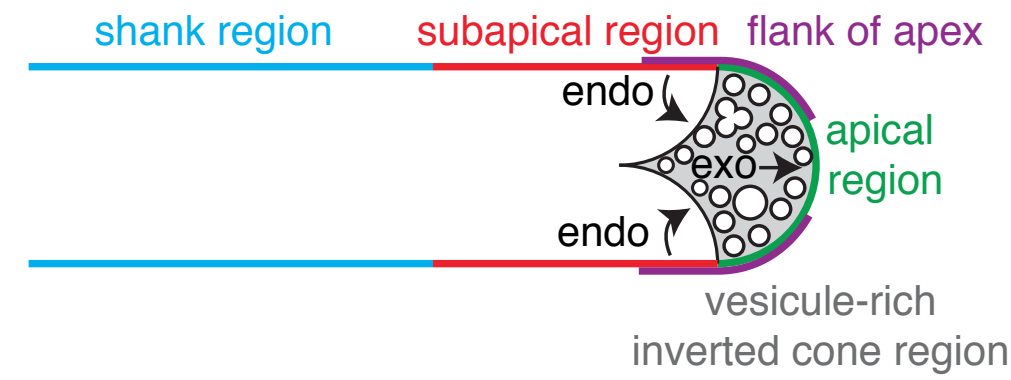

(b) pollen tube
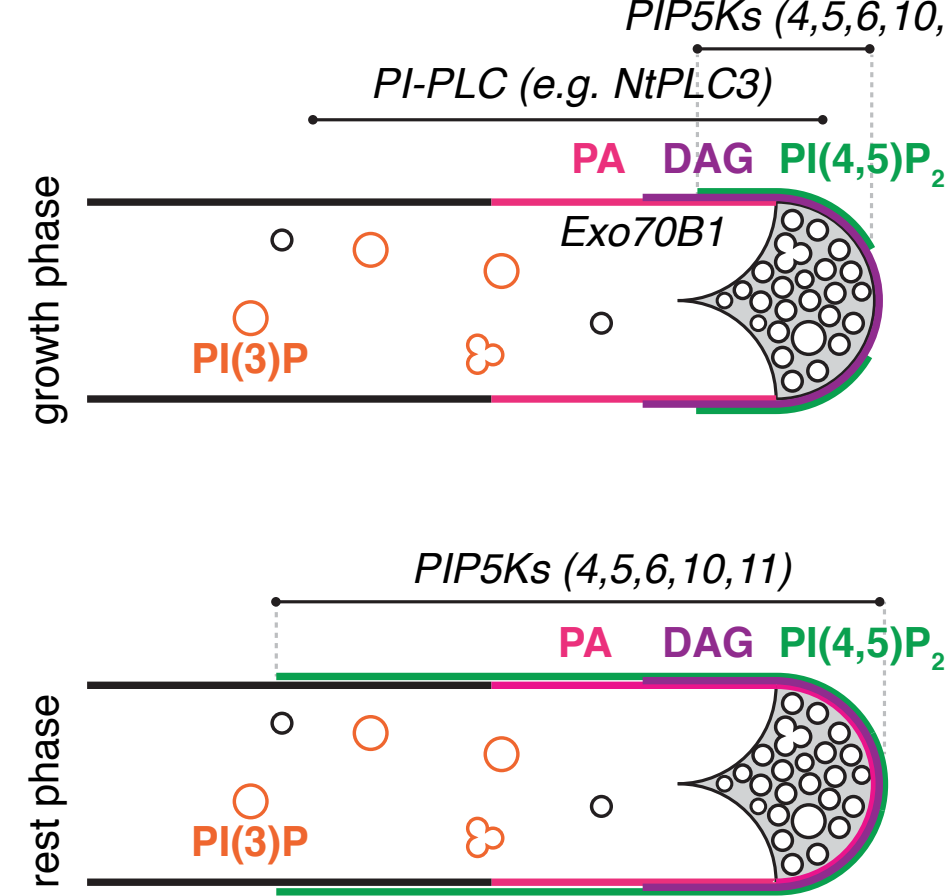

(c)

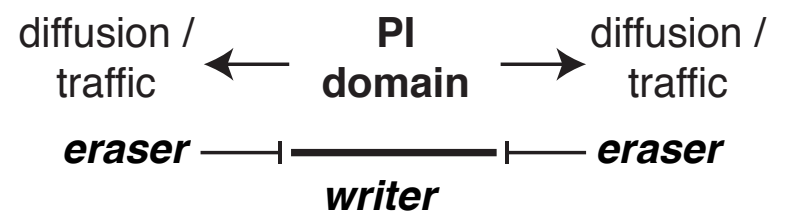

e.g. PI-PLC PIP5K PI-PLC

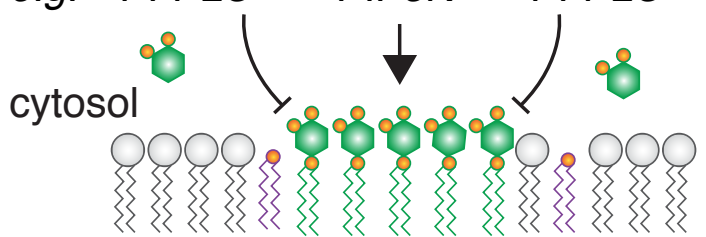

lumen

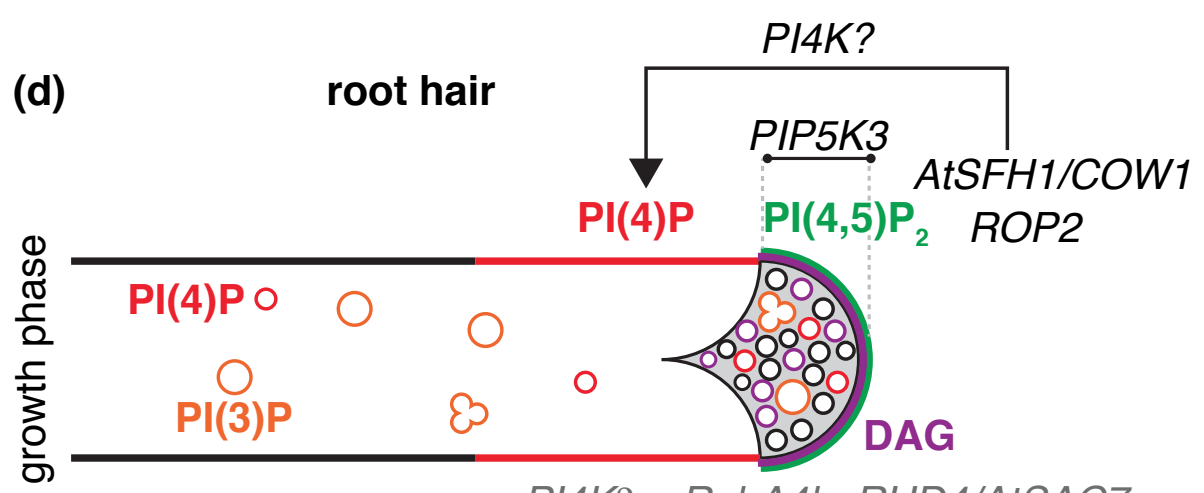

PI4Kßs, RabA4b, RHD4/AtSAC7

in vesicule-rich

inverted cone region 